\title{
Polyclonal rabbit anti-murine plasmacytoma cell globulins induce myeloma cells apoptosis and inhibit tumour growth in mice
}

\author{
Bo Mu $\cdot$ Jin-liang Yang $\cdot$ Lan-tu Gou $\cdot$ Yu-qin Yao $\cdot$ \\ Yan Zhou • Zhi-hui Cheng • Hua-shan Shi $\cdot$ Zhi-yong Li • \\ Yuan Wen · Fei Leng · Feng-yu Cui · Tian-tai Ma · Yu-quan Wei
}

Published online: 1 January 2011

(C) The Author(s) 2010. This article is published with open access at Springerlink.com

\begin{abstract}
Multiple myelomas (MMs) are etiologically heterogeneous and there are limited treatment options; indeed, current monoclonal antibody therapies have had limited success, so more effective antibodies are urgently needed. Polyclonal antibodies are a possible alternative because they target multiple antigens simultaneously. In this study, we produced polyclonal rabbit anti-murine plasmacytoma cell immunoglobulin (PAb) by immunizing rabbits with the murine plasmacytoma cell line MPC-11. The isolated PAb bound to plasma surface antigens in several MM cell lines, inhibited their proliferation as revealed by MTT assay, and induce apoptosis as indicated by flow cytometry, microscopic observation of apoptotic changes in morphology, and DNA fragmentation on agarose gels. The cytotoxicity of PAb on MPC-11 cell lines was both dose-dependent and time-dependent; PAb exerted a 50\% inhibitory effect on MPC-11 cell viability at a concentration of $200 \mu \mathrm{g} / \mathrm{ml}$ in $48 \mathrm{~h}$. Flow cytometry demonstrated that PAb treatment significantly increased the number of apoptotic cells (48.1\%) compared with control $\operatorname{IgG}(8.3 \%)$. Apoptosis triggered by PAb was confirmed by activation of caspase- $3,-8$, and -9 . Serial
\end{abstract}

\footnotetext{
B. Mu $\cdot$ J. Yang $(\bowtie) \cdot$ L. Gou $\cdot$ Y. Yao $\cdot$ Y. Zhou $\cdot$ Z. Cheng $\cdot$

H. Shi $\cdot$ Z. Li · Y. Wen $\cdot$ F. Leng · F. Cui · T. Ma ·

Y. Wei $(\bowtie)$

State Key Laboratory of Biotherapy, West China Hospital and School of Lifesciences, Sichuan University, Keyuan Road 4, Chengdu, Sichuan, People's Republic of China

e-mail: jinliang.yang@scu.edu.cn

Y. Wei

e-mail: yuquawei@vip.sina.com

B. $\mathrm{Mu}$

North Sichuan Medical College, Nanchong,

Sichuan 637000, China
}

intravenous or intraperitoneal injections of PAb inhibited tumour growth and prolonged survival in mice bearing murine plasmacytoma, while TUNEL assay demonstrated that $\mathrm{PAb}$ induced statistically significant apoptosis $(P<0.05)$ compared to control treatments. We conclude that $\mathrm{PAb}$ is an effective agent for in vitro and in vivo induction of apoptosis in multiple myeloma and that exploratory clinical trials may be warranted.

Keywords Polyclonal antibodies - Multiple myeloma · Apoptosis · Immunotherapy · DNA ladder

\section{Introduction}

Multiple myeloma (MM) accounts for approximately $10 \%$ of malignant hematologic neoplasms, and is resistant to conventional chemotherapy, high-dose radiotherapy, autologous stem cell transplantation, and allogeneic transplantation $[1,2]$. A promising alternative strategy is the development of specific immunotherapies selectively targeting myeloma cells [3]. A variety of tumour-associated antigens have been identified in myeloma cells, including CD20, CD40, CD52, MUC1, HM1.24, CYP1B1, SP17, PRAME, WT1, and heat shock protein gp96 [4-7]. In fact, an anti-CD20 monoclonal antibody, marketed as Rituximab, is already commercially available [8]. In addition, some monoclonal antibody therapies have progressed into clinical trials, including SGN-40 (anti-huCD40 MoAb) [9], anti-CD52 (alemtuzumab) [10], MRA (atlizumab), TRM-1 (Full Human TRAIL-R1 MoAb), AHM (anti-HM1.24 $\mathrm{MoAb}$ ) [11], and anti-CD126 (atlezumab) [12].

Unfortunately, myeloma cells are a heterogeneous population that express numerous cell surface antigens, including CD38, CD45, CD138, and adhesion molecules 
like VLA4 [13]. Different patients express different arrays of antigens; for example, CD20 can be detected in only $13-22 \%$ of patients [14]. Furthermore, multiple myeloma cells manifest intrinsic genetic mechanisms of drug resistance [15], further limiting treatment success, including that from available monoclonal antibodies. Targeting multiple antigens at the same time is a possible alternative but one that obviously requires the isolation and testing of efficient polyclonal antibodies.

Previous research suggested that polyclonal antibodies are a promising tumour therapy. For example, treating different myeloma cell lines with polyclonal rabbit antithymocyte globulin rATG resulted in specific activity against various surface proteins expressed on myeloma cells, such as CD19, CD20, CD27, CD38, CD126, and CD138, and induce significant apoptosis in myeloma cell lines by multiple pathways in vitro [16]. In addition, the rabbit-derived polyclonal anti-thymocyte globulin (thymoglobulin) targeted multiple plasma cell antigens in vitro and in vivo [13]. Although ATG (anti-thymocyte globulin) or ALG (anti-lymphocyte globulin) are produced by immunizing horses or rabbits with human thymocytes or activated T-cell or B-cell blasts, myeloma cells are actually terminally differentiated as neoplastic B cells with a low proliferative index and a long life span, so ATG or ALG alone may be inadequate for patients with a high myelomacell burden. Aside from immunocytes, myeloma cells can be used as the immunogen to prepare polyclonal antibodies. Indeed this strategy may be more specific and efficient because surface antigens were present in mouse myeloma cells but were not detected on cells of other tissues [17].

In this study, we isolated $\mathrm{PAb}$ by immunizing rabbits with murine MPC-11 plasmacytoma cells, a cell line that shares a number or common features with human MM cells [18]. We found that $\mathrm{PAb}$ could inhibit proliferation and induce apoptosis of multiple myeloma cell lines in vitro, and induced apoptosis after serial intravenous or intraperitoneal injection of PAb in mice carrying murine plasmacytoma in vivo. We observed tumour growth delay and prolonged survival relative to mice treated with a control IgG. These results suggest that broad specificity of polyclonal IgG may be related to multiple targets on multiple myeloma cells. We conclude that PAb is an effective agent for in vitro and in vivo induction of apoptosis in multiple myeloma and that exploratory clinical trials may be warranted.

\section{Materials and methods}

Animals and cell lines

New Zealand white rabbits and 6-8 week old BALB/c mice were purchased from the West China Experimental
Animal Center. Animal protocols for these experiments were approved by the West China Hospital Cancer Center's Animal Care Committee. In this study, the murine plasmacytoma cell lines MPC-11, SP2/0, and NS-1, along with the murine colon carcinoma cell line CT26 and murine melanoma cell line B16 were obtained from the American type culture collection (ATCC). Cells were cultured in RPMI-1640 (Gibco) containing 10\% heatinactivated foetal calf serum (FCS; Gibco) with 100 units/ $\mathrm{ml}$ penicillin, and 100 units $/ \mathrm{ml}$ streptomycin, in a humidified $5 \% \mathrm{CO}_{2}$ incubator at $37^{\circ} \mathrm{C}$.

\section{Rabbit immunizations and preparation of $\mathrm{PAb}$}

The PAb polyclonal antibody was generated by immunizing New Zealand white rabbits with MPC-11 cells using $1 \times$ to $5 \times 10^{7}$ per injection. The primary inoculation was with Freund's complete adjuvant (Sigma), followed by three boosts with Freund's incomplete adjuvant (Sigma) once every 10-14 days. The serum was pooled a week after the last injection. Blood was allowed to clot overnight at $4^{\circ} \mathrm{C}$ and serum was removed from the top of the mixture after centrifugation at $12000 \times g$. Immunoglobulin was isolated using an affinity chromatography system (AKTA explore, GE, USA) and freeze dried (Rlphr 1-4 LSC freeze drier, Christ, German). Antibodies were kept frozen at $-80^{\circ} \mathrm{C}$ until used. Control rabbit $\mathrm{IgG}$ was similarly purified from whole normal rabbit serum.

\section{ELISA}

For ELISA assays, MPC-11 cells were grown overnight in the wells of poly-lysine-coated 96 -well plates $\left(5 \times 10^{3}\right.$ cells/ well). The media was removed and the cells were washed three times in PBS. After washing, the cells were blocked with 5\% skim milk in blocking buffer (PBS containing $0.05 \%$ Tween-20 or PBST) for $1 \mathrm{~h}$ at room temperature. The blocking reagent was removed and the cells were washed three times in PBS before the PAb was added. The PAb was added at $0.25-2.5 \mu \mathrm{g} / \mathrm{ml}$ in dilution buffer (5\% skim milk in PBST) and cells were incubated for $1 \mathrm{~h}$ at room temperature. The antibody was removed and the cells were washed three times in PBST. The secondary goat anti-rabbit antibody linked to alkaline phosphatase (1:5000, Sigma) was added for 30 min. The cells were then washed three times in PBST. Subsequently, alkaline phosphatase substrate BCIP/NCP (Sigma) was added and absorbance was measured at $450 \mathrm{~nm}$ using a 96-well plate reader (Molecular Devices, M5, USA).

Immunofluorescence stain of multiple myeloma cells

The tumour cell lines listed above were grown to logarithmic phase, harvested, and washed three times with PBS. Cell 
lines were blocked with 5\% skim milk in PBST for $1 \mathrm{~h}$ at room temperature. The blocking reagent was removed and 1:1000 PAb or control rabbit IgG in PBST containing 5\% skim milk was added for $30 \mathrm{~min}$. The antibody was removed and the cells were washed three times in PBST. The secondary FITC-goat anti-rabbit IgG antibody (1:500; Beijing Zhong Shan-Golden Bridge Biological Technology CO., LTD, China) was added and incubated for $30 \mathrm{~min}$. Cells were washed three times in PBST and 10,000 cells were harvested for flow cytometry. (Beck-man-coulter, USA).

Localization of PAb binding with antigens on multiple myeloma cells

Cultured MPC-11 cells at $5 \times 10^{6}$ per well were fixed for 5 min with $100 \mu \mathrm{l} 4 \%$ formaldehyde in phosphate-buffered saline at $\mathrm{pH} 7.6 ; 30 \mu \mathrm{l}$ of the fixed cell suspension was spread on microscope slides for cell smears. After drying, cells were permeated by treatment for 5 min with $0.5 \%$ Triton X-100 in buffer containing $10 \mathrm{mM}$ Hepes, $300 \mathrm{mM}$ sucrose, $3 \mathrm{mM} \mathrm{MgCl}_{2}$, and $50 \mathrm{mM} \mathrm{NaCl}, \mathrm{pH}$ 7.4. Cells were incubated with $\mathrm{PAb}$ or control rabbit $\mathrm{IgG}$ (dilution of 1:1000) overnight at $4^{\circ} \mathrm{C}$. The antibody was removed and the cells were washed three times in PBST. The secondary FITC-goat anti-rabbit IgG antibody (1:500; Beijing Zhong Shan-Golden Bridge Biological Technology CO., LTD, China) was added and cells were incubated in a humidified chamber for $30 \mathrm{~min}$. The antibody was removed and the cells were washed three times in PBST, stained with Hoechst33258 for $5 \mathrm{~min}$, washed with PBS, and imaged under a fluorescent microscopy (Zeiss Photoscope Imager).

\section{Cell viability analysis}

Cell viability analysis was determined by 3-(4,5-dimethylthiazol-2-yl)-2, 5-diphenyltetrazolium bromide (MTT, Sigma) assay. Briefly, cultured MPC-11 cells, normal mouse spleen cells, or B and $\mathrm{T}$ cells purified from splenocytes by nylon wool column [19], were seeded in 96-well plates at a volume of $100 \mu \mathrm{l}$ per well and incubated for $24 \mathrm{~h}$. The cells were treated with normal saline (NS), control rabbit IgG, or with $\mathrm{PAb}$ for 24,48 , or $72 \mathrm{~h}$ at $37^{\circ} \mathrm{C}$. The MTT assay was then performed by dissolving the reaction product in DMSO and measure the absorbance at $540 \mathrm{~nm}$. The cells treated with NS served as the control indicator of $100 \%$ cell viability. For caspase inhibition, cells were incubated with the general caspase inhibitor zVAD-fmk $(100 \mu \mathrm{M})$ for $1 \mathrm{~h}$ prior to addition of PAb and then cultured for $48 \mathrm{~h}$ as above.

Apoptosis analysis by DNA fragmentation assay

The MPC-11 cells were incubated in RPMI1640 medium for $20 \mathrm{~h}$ with the agents indicated. DNA preparations were obtained by following a previously described procedure [20]. Briefly, MPC- 11 cells $\left(5 \times 10^{6}\right)$ were lysed in $0.5 \mathrm{ml}$ lysis buffer containing $5 \mathrm{mM}$ Tris- $\mathrm{HCl}(\mathrm{pH} 8), 0.25 \%$ Nonidet P-40, $1 \mathrm{mM}$ EDTA, and $200 \mu \mathrm{g} / \mathrm{ml}$ RNaseA (Sigma) and incubated at $37^{\circ} \mathrm{C}$ for $1 \mathrm{~h}$. Cells were then treated with proteinase $\mathrm{K}$ at a concentration of $300 \mu \mathrm{g} / \mathrm{ml}$ for $1 \mathrm{~h}$ at $37^{\circ} \mathrm{C}$. Following the addition of $6 \times$ loading buffer, $25 \mu$ lysate samples were subjected to electrophoresis on $1.5 \%$ agarose gels at $50 \mathrm{~V}$ for $3 \mathrm{~h}$. DNA was stained with gold view (Sigma).

\section{Apoptosis analysis by flow cytometry assay}

The MPC-11 cells $\left(3 \times 10^{5}\right)$ were plated in 6 -well plates and treated with normal saline, control $\operatorname{IgG}(200 \mu \mathrm{g} / \mathrm{ml})$, or PAb $(200 \mu \mathrm{g} / \mathrm{ml})$. After $48 \mathrm{~h}$, flow cytometric analysis was performed to detect G1 cells and apoptotic cells. Briefly, cells were suspended in $1 \mathrm{ml}$ hypotonic fluorochrome solution containing $50 \mu \mathrm{g} / \mathrm{ml}$ propidium iodide in $0.1 \%$ sodium citrate plus $0.1 \%$ Triton $\mathrm{X}-100$, and analyzed by a flow cytometer. Apoptotic cells were defined as cells with DNA content less than that of G1 phase cells in the cell cycle distribution.

\section{Western blotting}

The activation of caspase- $3,-8$, and -9 were determined by Western blotting. The MPC- 11 cells $\left(3 \times 10^{5}\right)$ were plated in 6-well plates and treated with NS, control $\operatorname{IgG}(200 \mu \mathrm{g} / \mathrm{ml})$, or $\mathrm{PAb}(200 \mu \mathrm{g} / \mathrm{ml})$. After $48 \mathrm{~h}$, cells from each treatment group were lysed in buffer $(2 \times$ PBS, $0.1 \%$ SDS, $1 \%$ Nonidet P-40, $0.5 \%$ sodium deoxycholate, and $0.1 \mathrm{mM}$ phenylmethylsulfonyl fluoride), and then homogenized with an ultrasonic homogenizer. Proteins ( $25 \mu \mathrm{g} / \mathrm{lane})$ were separated by SDSPAGE. The separated proteins were transferred to polyvinylidene fluoride (PVDF) membranes by electroblotting. The membranes were blocked in 5\% (w/v) skim milk in TBST (20 mM Tris, $500 \mathrm{mM} \mathrm{NaCl}, 0.1 \%$ Tween-20, pH 7.6), and incubated overnight at $4{ }^{\circ} \mathrm{C}$ with primary antibodies for caspase-3 (Cell Signaling Technology), anti-murine caspase- 8 (Thermo Scientific), or anti-murine caspase-9 (Cell Signaling Technology). The membrane was then washed three times with TBST and incubated with a secondary antibody conjugated with horseradish peroxidase at a 1:5000 dilution for $1 \mathrm{~h}$, followed by visualization with Vectastain ABC (Vector Laboratories, Burlingame, CA).

Antitumour effect of PAb to mouse models established with MCP-11 cells

Two tumour mouse models were developed. Tumours were established by either a single subcutaneous (s.c.) injection of $2 \times 10^{5}$ MPC-11 tumour cells into the right flank or one 
intraperitoneal (i.p.) injection of $2 \times 10^{6}$ MPC-11 tumour cells. Treatments were initiated on the seventh day after tumour cell inoculation in the s.c. tumour model (a time when tumour nodules were palpable), or on the fifth day after tumour cell inoculation for the i.p. tumour model. All animals were randomized into three groups with six mice per group, and administered PAb (200 $\mu \mathrm{g} / \mathrm{dose})$, control IgG $(200 \mu \mathrm{g} / \mathrm{dose})$ or NS once every two days in a volume of $100 \mu \mathrm{l}$, for a total of seven administrations. The s.c. tumour model mice were treated via tail vein injection and the mice in the i.p. tumour model group received treatment by intraperitoneal injection. The volume of a subcutaneous tumour nodule was calculated as length $\times$ breadth $^{2} / 2$, and the intraperitoneal nodules were counted using a dissecting microscope.

Terminal deoxynucleotidyl transferase-mediated dUTP nick end labeling (TUNEL) assay

Cell apoptosis in vivo was investigated using a terminal deoxynucleotidyl transferase-mediated dUTP nick end labeling (TUNEL) assay according to the manufacturer's instructions (Promega, USA). Three tumour nodules per group in the s.c. tumour model were analyzed at $48 \mathrm{~h}$ after the last treatment.

\section{Statistical analysis}

The statistical significance of results in all of the experiments was determined by Student's $t$ test and ANOVA using SPSS 13 analysis software. Findings were regarded as significant if $P<0.05$.

\section{Results}

Production and characterization of PAb

There was about 3-10 fold greater binding of PAb to MPC11 cells compared with control IgG and binding efficacy was dose-dependent over the range of $0.25-2.5 \mu \mathrm{g} / \mathrm{ml} \mathrm{PAb}$ (Fig. 1a). We analysed binding of PAb to the plasma membrane of multiple myeloma cell surface antigens by flow cytometry and fluorescence microscopic analysis. The polyclonal antibody was much more effective at recognizing surface antigens than control IgG in MPC-11 murine myeloma cells, as well as in SP2/0 and NS-1 cells. However, PAb did not bind non-myeloma cell lines, such as the murine colon carcinoma cell line CT26 and murine melanoma cell line B16 (Fig. 1b, c). These results demonstrate that PAb polyclonal antibodies specifically targeted myeloma cells.
$\mathrm{PAb}$ inhibited myeloma cell proliferation

We first determined the effect of PAb on growth of MM cell lines using the MTT assay in the presence or absence of PAb. As shown in Fig. 2, PAb reduced cell number in a dose-dependent and time-dependent manner. The doseresponse and time-dependent curves (Fig. 2a) revealed that PAb at concentrations of $200 \mu \mathrm{g} / \mathrm{ml}$ or greater were most effective at reducing the cell number. The maximum effect was seen at $72 \mathrm{~h}$ incubation with only slightly lower activity at $48 \mathrm{~h}$. Similar results were obtained from NS-1 and SP2/0 cell lines (data not shown) suggesting that PAb could reduce cell number by inhibiting proliferation or by inducing cytotoxicity in multiple myeloma cell lines. As these cells proliferate slowly, cytotoxicity was the most likely mechanism and was investigated in subsequent experiments.

To determine whether complement derived from FCS in the culture medium could contribute to the observed cytotoxicity, we repeated these experiments using non-heat inactivated (complement-containing) FCS (Fig. 2b). These experiments suggested that both complement-mediated and complement-independent mechanisms contributed to the observed reduction in MM number. In the absence of detectable complement activity, MPC-11 cell proliferation was inhibited by up to $56.3 \%$ at $200 \mu \mathrm{g} / \mathrm{ml}$ PAb $(P<0.05$; Fig. 2a), and similar results were also shown in NS-1 and SP2/0 cell lines (data not shown). All subsequent experiments were performed using heat-inactivated FCS to further characterize the complement-independent mechanisms of MM cytotoxicity induced by PAb. In addition, we found that PAb did not effect the growth of normal mixed populations of splenocytes (Fig. 2c). We also purified B and T cells from splenocytes by nylon wool column and found that PAb did not inhibit these immunocytes (Fig. 2c).

\section{PAb induced apoptosis of myeloma cells}

A decrease in myeloma cell proliferation may also result from the induction of apoptosis, so we determined whether $\mathrm{PAb}$ induced apoptosis using light microscopy, flow cytometry, and DNA fragmentation analysis. The PAbtreated MM cells appeared morphological distinct from controls, with condensation of the cytoplasm and membrane blebbing (Fig. 3a-c). In addition, agarose gel electrophoresis demonstrated that PAb-treated cells exhibited a ladder-like pattern of DNA fragments consisting of multiples of approximately 180-200 bp, consistent with endonuclease-induced DNA fragmentation (Fig. 3d). Furthermore, flow cytometry indicated that PAb treatment significantly increased the number of apoptotic cells compared with the control treatments (PAb-treated, 48.1\%; NS-treated, 7.0\%; control Rabbit IgG-treated, 8.3\%) 
Fig. 1 Binding of PAb to murine MPC-11 plasmacytoma cells. a ELISA results of PAb binding to MPC-11 cells. Control rabbit IgG and PAb was incubated with MPC-11 at dilutions of $0.25-2.5 \mu \mathrm{g} / \mathrm{ml}$. After the addition of alkaline phosphatase conjugated secondary antibody, absorbance was measured at $450 \mathrm{~nm}$.

Represented here is the mean of 4-6 wells \pm S.D. for every dilution. b Indirect immunofluorescence assay of $\mathrm{PAb}$ on myeloma and nonmyeloma cell lines by flow cytometry. Grey line represents 1/2000 PAb dilutions reacted with MPC-11 (left panel), SP2/0 (upper part, left panel) and NS-1 (upper part, right panel); murine melanoma cell line B16 (lower part, left panel) and murine colon carcinoma cell line CT26 (lower part, right panel). Black line represents the control IgG diluted 1/2000 used as negative control. c Indirect immunofluorescence assay of PAb on MPC-11 by

fluorescence microscopy with FITC-goat anti-rabbit IgG (left; green fluorescence) and with hoechst33258 (middle; blue fluorescence). Upper line represents cells treated with $\mathrm{PAb}$, and lower line represents cells treated with control IgG. Merged images (right) show localization of PAb on MPC-11 cells $(\times 400)$ (Color figure online)
A

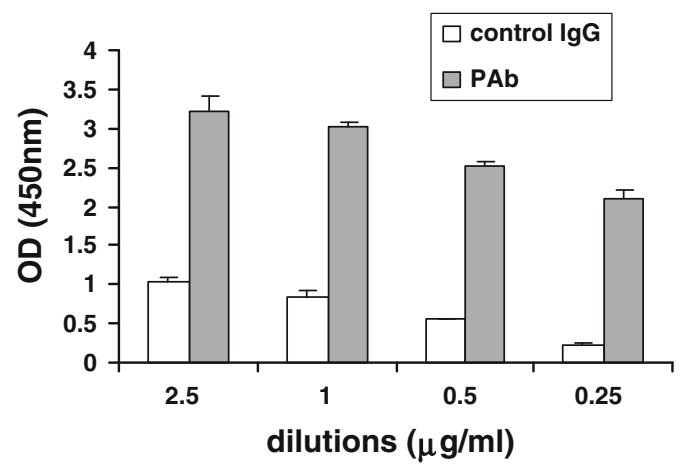

B
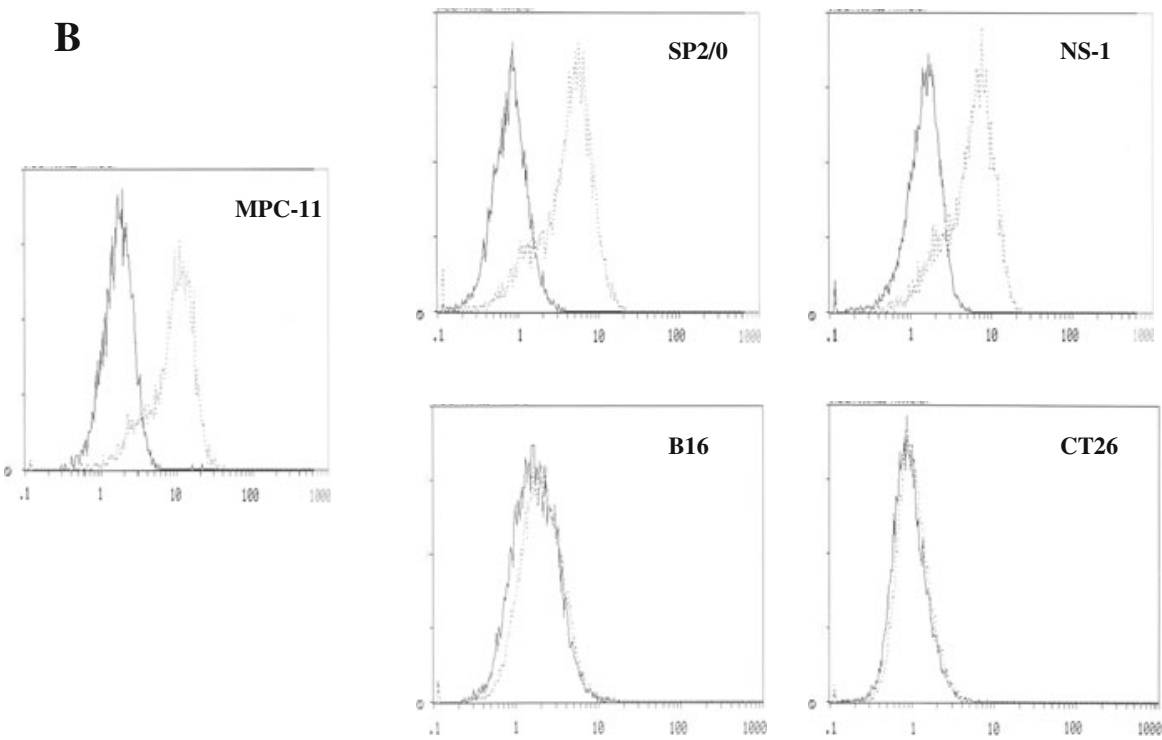

C
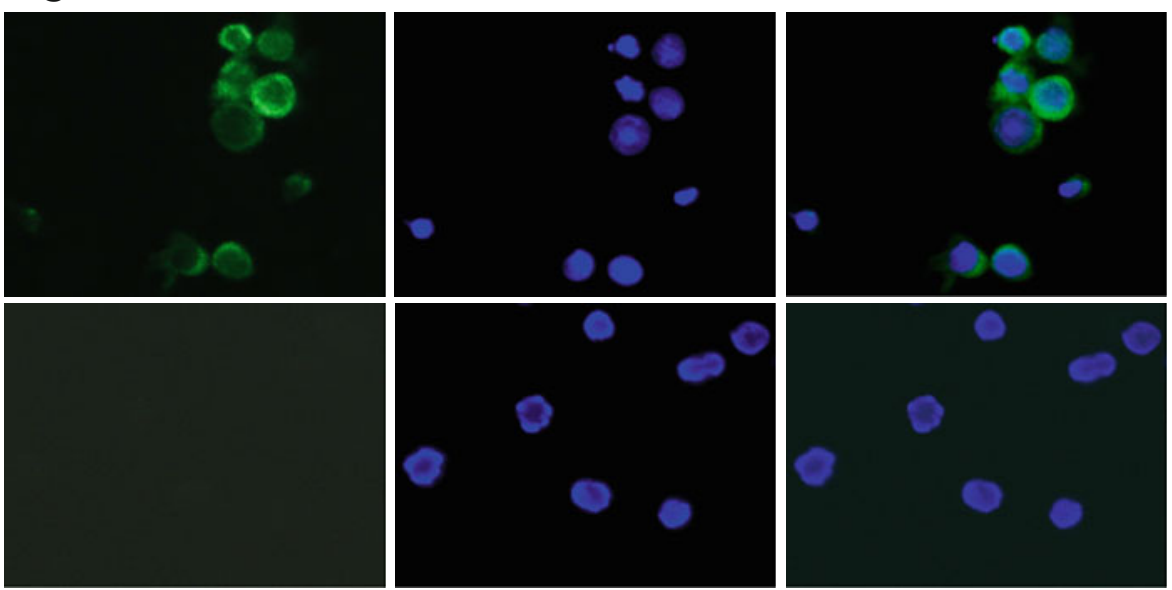

(Fig. 3E). To confirm that PAb induced apoptosis of myeloma cells, we examined the activation of caspases-3, -8 , and -9 by Western blotting (Fig. 3f). Indeed, treatment with PAb led to increased enzyme activities of these caspases at $48 \mathrm{~h}$ post-treatment and ultimately causing apoptosis by DNA fragmentation. In addition, the broadspectrum caspase inhibitor of z-VAD-fmk inhibited PAbinduced MPC-11 cell death (Fig. 3g), confirming that caspases are activated following PAb treatment and are necessary for apoptosis in MPC-11cells. Thus, PAb inhibited proliferation and induced apoptosis in a myeloma cells in vitro.

$\mathrm{PAb}$ reduced tumour growth in an animal model of myeloma

To examine the anti-tumour activity of PAb in vivo, 6-8 week-old $\mathrm{Babl} / \mathrm{c}$ mice were injected with MPC-11 
Fig. 2 The PAb polyclonal antibody was cytotoxic to the myeloma cell MPC-11 line. a MPC-11 cells were cultured with or without $\mathrm{PAb}$ in medium containing inactivated FCS at $37^{\circ} \mathrm{C}$ for 24,48 , or $72 \mathrm{~h}$. Cell viability was measured by a colorimetric assay utilizing MTT. b MPC-11 cells were cultured with or without $\mathrm{PAb}$ in medium containing $\mathrm{FCS}$ at $37^{\circ} \mathrm{C}$ for 24,48 , or $72 \mathrm{~h}$ and cell viability was measured MTT. c MTT analysis of normal mice spleen cells and purified B and $\mathrm{T}$ cells from splenocytes treated with $\mathrm{PAb}$
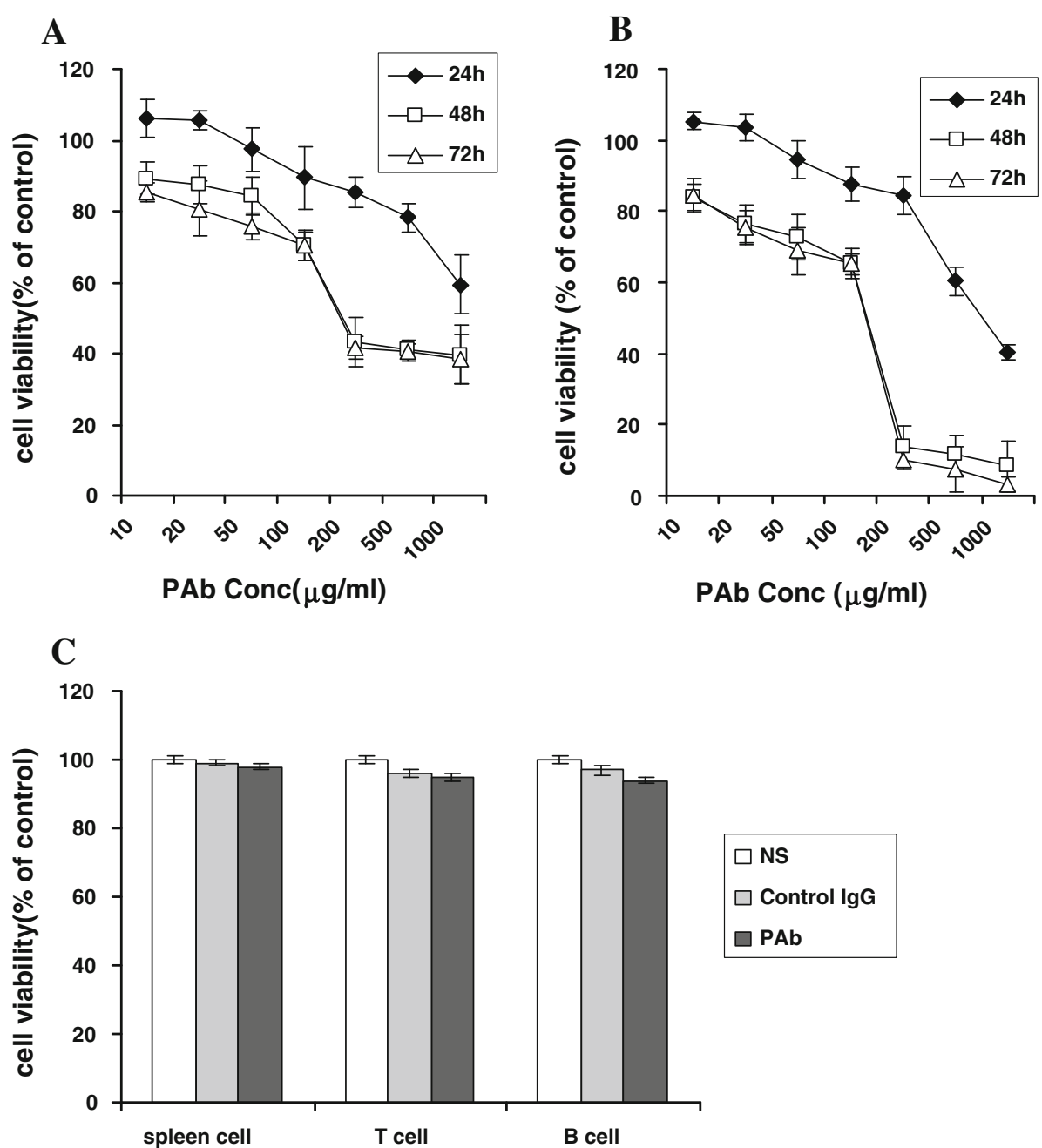

cells subcutaneously or intraperitoneally as described in the methods section. On necropsy, analysis of abdominal contents revealed large multiple large tumour nodules in $\mathrm{NS}$ and control IgG-treated mice. The number of visible tumour nodes (NS, $35 \pm 6.4$; control $\mathrm{IgG}, 46.3 \pm 6.3$ ) was drastically reduced in PAb-treated mice $(4.2 \pm 6.1)$ (Fig. 4). Tumour size were similar in both control groups (NS-treated, $1.4 \pm 0.6 \mathrm{~cm}^{3}$; control IgG-treated, $1.5 \pm 0.8 \mathrm{~cm}^{3}$ ) and were principally dispersed around the small bowel with sparsely seeding on at mesentery and diaphragm. In contrast, the abdominal contents from the $\mathrm{PAb}$ treated group showed smaller $\left(0.6 \pm 0.3 \mathrm{~cm}^{3}\right)$ tumour nodules localized to small bowel mesentery. The results showed that treatment with PAb resulted in a significant inhibition of tumours growth compared with NS treatment $(P<0.01)$ and control IgG treatment $(P<0.05)$.

To assess the long-term antitumour effect of PAb, subcutaneous MPC-11 cell implantations were developed to study tumour growth through measurement of their volumes in vivo. The results showed that the treatment with $\mathrm{PAb}$ resulted in a significantly increased regression of established tumours as compared with treatment with NS or control IgG (Fig. 5). The average tumour volume in the $\mathrm{PAb}$ group was stable for the duration of administration, but the average tumour volume in the NS and control $\mathrm{IgG}$ groups still grew after (sham) treatment. The inhibition rate was $61.6 \%$ relative to the NS group and $65.2 \%$ compared with the control IgG group (Fig. 5a). In addition, treatment with $\mathrm{PAb}$ resulted in a significantly decreased tumour weight compared with treatment with NS or control IgG $(P<0.05$, Fig. 5b). Furthermore, survival was also significantly prolonged when MPC-11-bearing mice were treated with PAb. The median survival in the NS group was 32 days and treatment with control $\mathrm{IgG}$ did not prolong mice survival further. In contrast, median survival in MPC11 bearing mice with PAb treatment increased to more than 60 days (Fig. 5c). Thus, PAb possessed anti-tumour activity in vivo. In order to test whether apoptosis was the mechanism by which PAb produced anti-tumour effects in vivo, we performed a TUNEL assay on histological sections. As shown in Fig. 6, there were more apoptotic cells (with green nuclei) in tumour tissues from PAb treated 
A

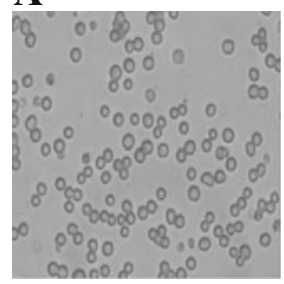

B

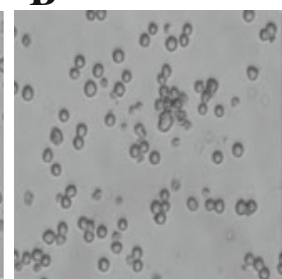

C

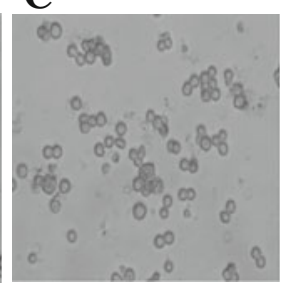

D
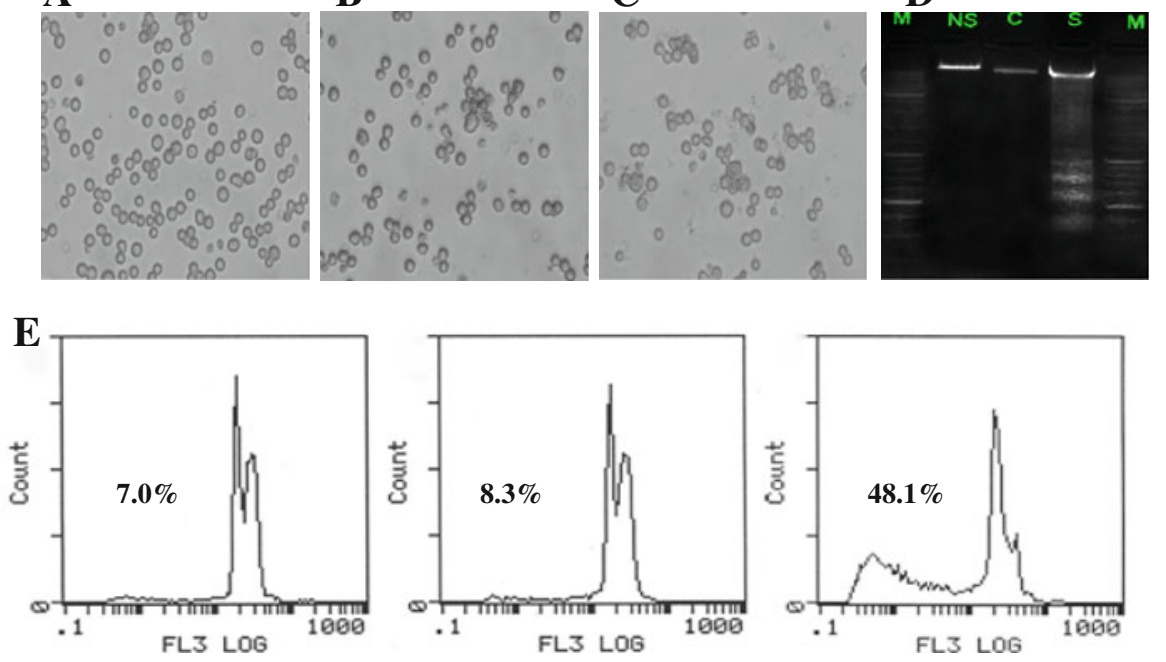
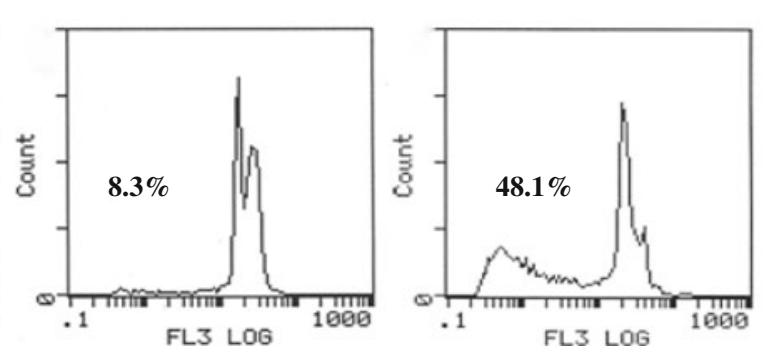

DNA content (PI fluorescence)
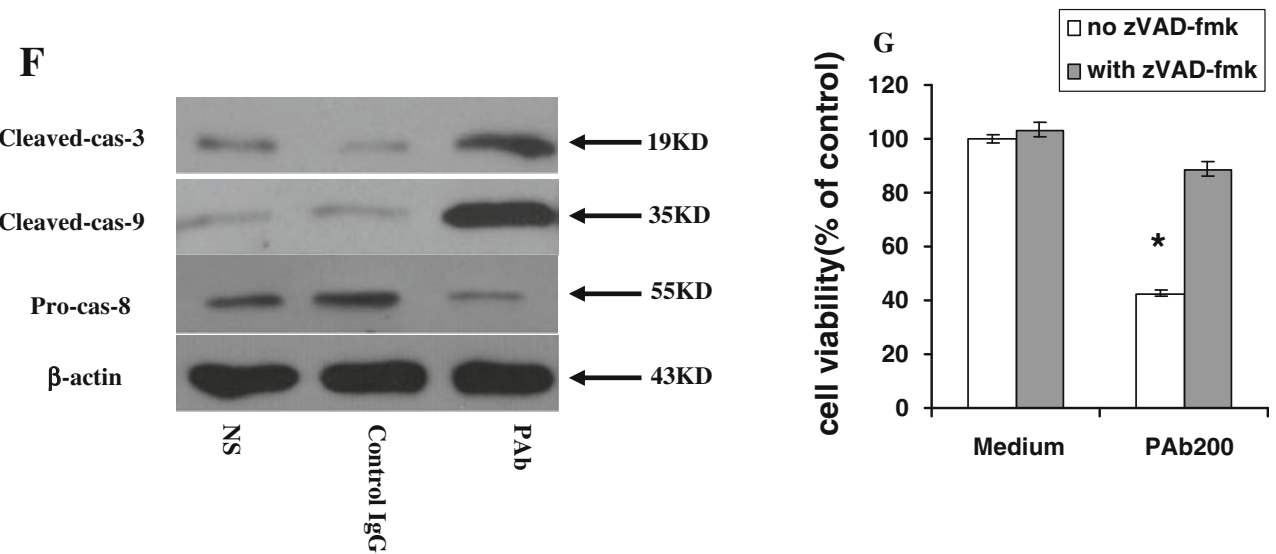

Fig. 3 PAb-induced apoptosis in myeloma cell lines. a-c The MPC11 was cultured in the presence of NS, control IgG, or PAb $(200 \mu \mathrm{g} /$ $\mathrm{ml}$ ) in microtiter plates for $48 \mathrm{~h}$ before photography. d MPC-11 cells were incubated with PAb $(200 \mu \mathrm{g} / \mathrm{ml})$ in culture medium at $37^{\circ} \mathrm{C}$. At $48 \mathrm{~h}, 10^{6}$ cells were removed and DNA was isolated. $M$ marker, $N S$ normal saline group, $C$ control $\mathrm{IgG}, S$ PAb group. e Flow cytometric analysis revealed the proportion of sub-G1 cells (apoptotic cells) to be $7.0 \%$ in the NS group (left panel), $8.3 \%$ in the control IgG group (middle panel), and $48.1 \%$ in PAb-treated cells (right panel). f PAbinduced activity of caspase-3, -8 , and -9 in MPC-11 cells. MPC-11 cells were treated with $200 \mu \mathrm{g} / \mathrm{ml} \mathrm{PAb}$ (right lane), the same

mice than from either control $\mathrm{IgG}$ and NS treated mice $(P<0.05)$.

\section{Discussion}

The clinical efficacies of conventional MM therapies, including chemotherapy, high-dose radiotherapy, or allogeneic stem cell transplants are poor due to the heterogeneity of MMs, the presence of drug-resistance mechanisms, and the structural complexity of tumours within connective concentration of control IgG (middle lane), or NS (left lane) for $48 \mathrm{~h}$ and then lysed as described in "Materials and methods". Protein extracts were immunoblotted to monitor the activation of caspase-3, -8 , and -9 . $\beta$-actin was used as the loading control. $\mathbf{g}$ Myeloma cells were pretreated with the caspase inhibitor zVAD-fmk at $100 \mu \mathrm{M}$ for $1 \mathrm{~h}$ before treatment with PAb at $200 \mu \mathrm{g} / \mathrm{ml}$ for $48 \mathrm{~h}$. Cell viability was assessed by MTT assay. *Represents the significant difference in cell viability in presence of zVAD-fmk versus PAb treatment alone. Bar graph indicates the mean $\pm \mathrm{SD}$ of 3 independent experiments $(P<0.05)$

tissue [21]. Immunotherapy based on antibodies offers a possible alternative to cure malignancy [22]. Targeting cell surface antigens using monoclonal antibodies represents a very attractive approach [23]. Rituximab demonstrated impressive clinical responses and became the first $\mathrm{mAb}$ approved by the FDA for use in human malignancy [24]. Some other promising antibodies have also been evaluated in preclinical and clinical studies [14, 25-28]. However, no universal target common to all myeloma cells has been found and patients express different sets of surface antigens. Therefore, no one monoclonal antibody will be 
Fig. 4 Intraperitoneal growth of murine MM.

a-c Representative gross abdominal findings at necropsy from specimens collected from NS, control IgG, and PAbtreated mice. The white arrows point to the myeloma growth in the abdominal cavity from one of each group specimens. d The mean number of tumour nodules in each group of mice. Bar graph indicates the mean $\pm \mathrm{SD}$ $(n=5)$. *Represents the significant difference in the PAb-treated mice relative to NS group $(P<0.01)$ and control IgG treated mice $(P<0.05)$
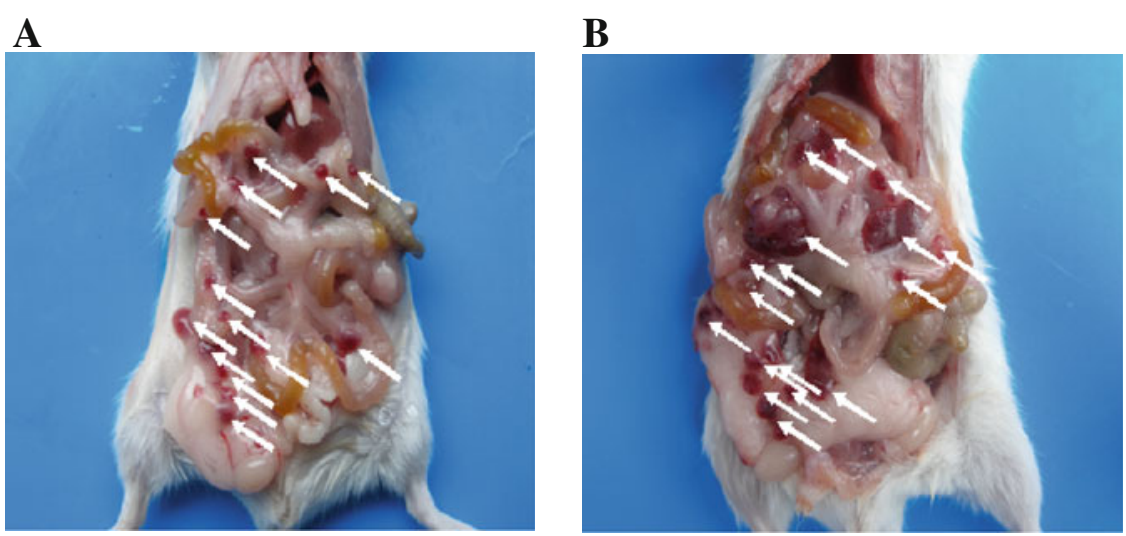

C

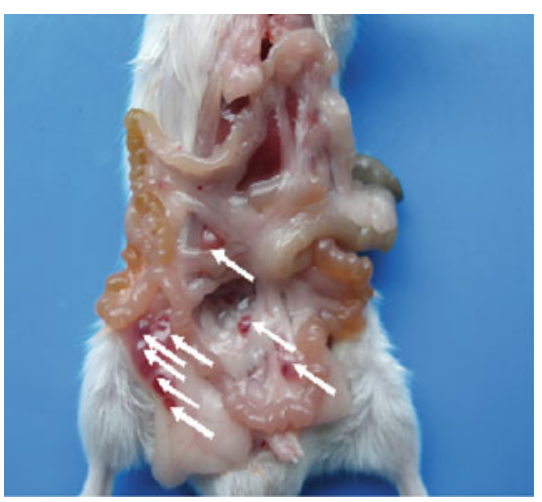

D

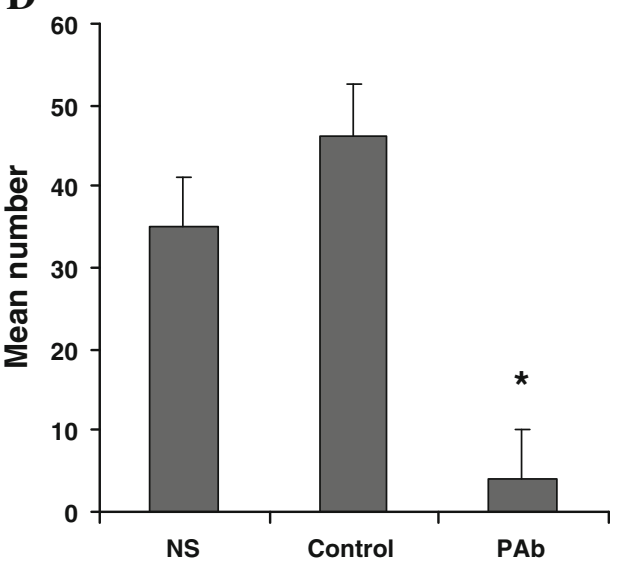

effective in all patients [29], while drug resistance will eventually may hamper chemotherapy [15, 30]. Present monoclonal antibody therapies are not optimal and more effective antibodies are urgently needed.

Polyclonal antibodies are a possible alternative as they possess several inherent advantages. First, polyclonal antibodies raised against a selected target in hyper-immunized animals recognize the most immunogenic epitopes and so are 'naturally selected' for by the host [29]. This may also permit the development and manufacture of polyclonal antibodies that recognize multiple surface proteins and simultaneously activate multiple biochemical pathways leading to cell death. Second, polyclonal antibody therapeutics may be advantageous due to the high density of antibodies binding to the tumour cell surface. This would promote enhanced cross-linking of Fc receptors on effectors cells and efficient C1q binding in immunodeficient patients [31]. Finally, the PAb could preclude the development of tumour cell "escape variants", because the probability that tumour cells will simultaneously lose all target epitopes is extremely small.

Two available polyclonal antibodies, ATG or ALG, were obtained by immunizing horses or rabbits with human thymocytes or activated T- or B-cell blasts. One potential problem with this strategy is that the relative concentrations of B-cell and T-cell antibodies in the polyclonal antibody preparations have not been determined. It is therefore possible that the clinical anti-myeloma cell activity of ATG may be inadequate to deal with patients with high myeloma-cell burdens. On the other hand, there is a risk of infection with ATG therapy in myeloma due to its ability to deplete the T-cell count. Infections related to T-cell depletion tend to be of viral origin, including Epstein-Barr virus, adenovirus, cytomegalovirus, parvovirus, and herpes viruses [16]. Compared with these polyclonal antibodies, our PAb may be an improvement because PAb was obtained by immunizing rabbits with whole living murine multiple myeloma cells. To our knowledge, this is the first time that PAb has been produced by immunizing rabbits with whole living tumour cells as antigens. An additional advantage is that all the molecules on the tumour cells, including unknown molecules, are exposed to the immune system. In addition, only surface antigens present in mouse myeloma cells will evoke an immune response, not antigens expressed by beneficial immunocytes or other cells [17]. Our antibody had high specificity for MM cells, could recognize multiple epitopes simultaneously, and showed low binding to nontumour cells. This allowed PAb to kill tumour cells at relatively low doses. Our study also confirmed that PAb 
Fig. 5 Inhibitory effect of PAb on tumour growth in a mouse model injected subcutaneously with MPC-11. a After mice bearing subcutaneous MPC-11 tumour nodules were injected (i.v.) with $\mathrm{PAb}$, a significant decrease in tumour size was noted that was not seen among the NS-treated and control IgGtreated mice. b Comparison of average tumour humid weights between all groups. *Represents significant difference between the PAb treatment group and both control groups $(P<0.05)$. Bar graph indicates the mean $\pm \mathrm{SD}(n=5)$. c The mice treated with $\mathrm{PAb}$ demonstrated better survival accompanied with tumour growth reduction
A

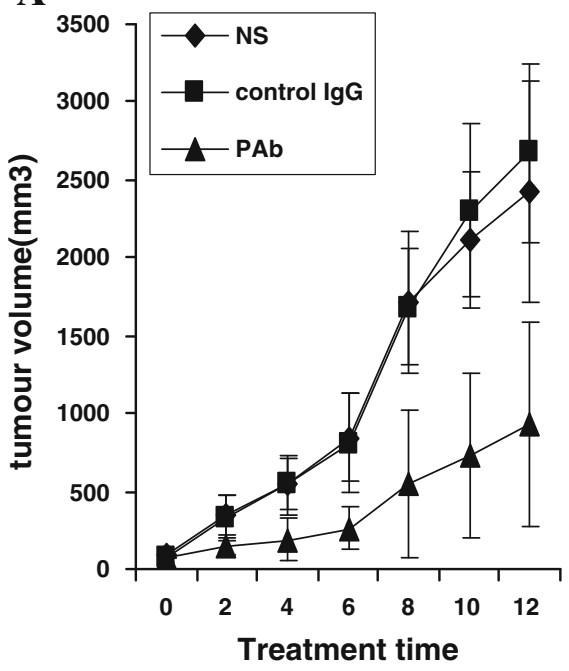

B

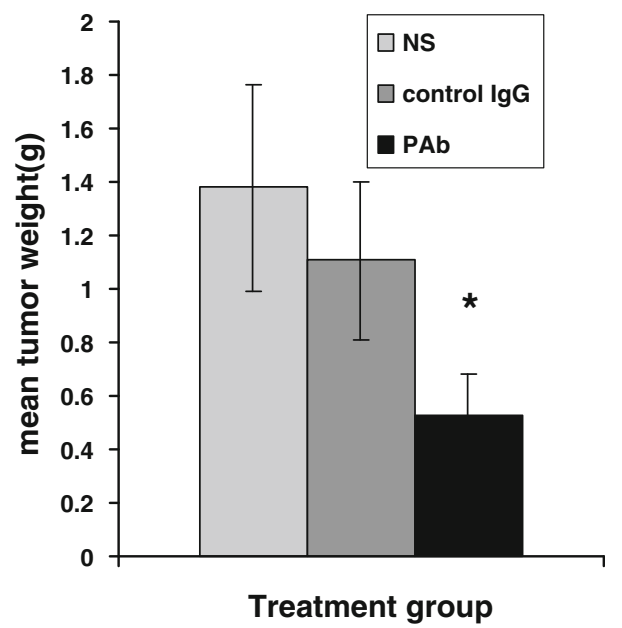

C

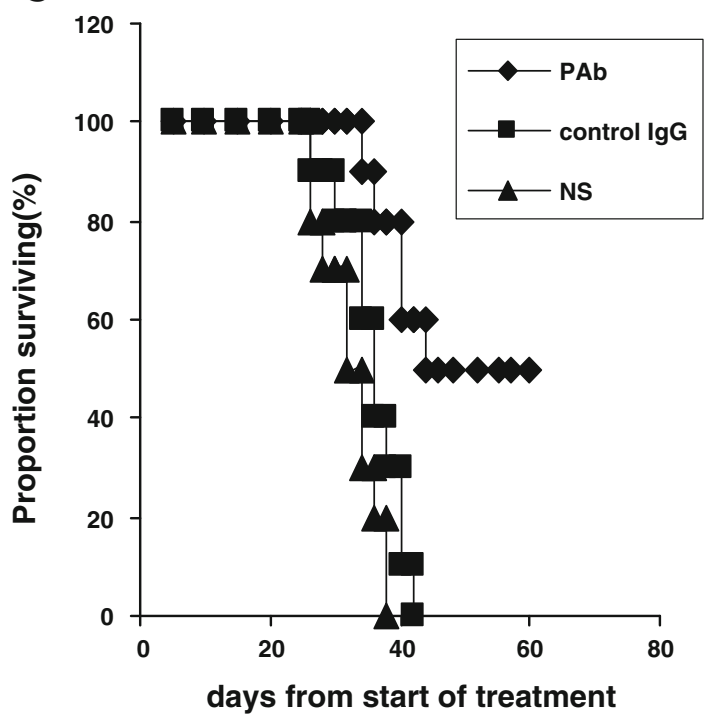

significantly inhibited growth and induced apoptosis in myeloma cells, but normal spleen cells and purified B and $\mathrm{T}$ cells from splenocytes were not killed by PAb treatment (Fig. 2c). These results underscore the specificity of this technique and indicate that PAb will not induce immunosuppression.

A number of studies have shown that cells undergoing apoptosis have typical biochemical and morphological patterns, such as condensation of the cytoplasm, membrane blebbing, and endonuclease-induced DNA fragmentation [32-35]. Here we demonstrated that PAb induced apoptosis in multiple murine myeloma cell lines was accompanied by the usual hallmarks of apoptosis as revealed by microscopic study of changes in cell morphology, DNA laddering, and flow cytometry (Fig. 3). Furthermore, PAb delayed tumour growth and prolonged life span by in mice bearing murine plasmacytoma (Fig. 5). Histological of
TUNEL-stained tumour sections showed that PAb was able to induce statistically significant apoptosis $(P<0.05)$ compared to control treatments (Fig. 6) and reduce tumour volume (Fig. 5).

Previous studies have implicated a number of different mechanisms in the anti-myeloma activity of polyclonal antibodies like rATG and ALG. A role for complement was suggested by results that showed enhanced cytotoxicity of thymoglobulin when cells were incubated in the presence of complement [36]. In our study, PAb also inhibited proliferation of $\mathrm{MM}$ in the presence of complement (Fig. 2b); however, the cytotoxic effects on myeloma cells were also observed in the absence of complement (Fig. 2a). The importance of the caspases in tumour cell death has been highlighted in complement-independent anti-MM cell viability assays that demonstrated significant rescue in the presence of caspase inhibitors. In our study, we showed that 
Fig. $6 \mathrm{PAb}$ induced apoptosis in vivo as revealed by TUNEL assay. a-c Sections from the tumour-bearing mice treated with NS, control IgG, or PAb, were stained with FITC-dUTP as described in materials and methods $(\times 200)$. d An apparent increase in the number of apoptotic cells and apoptotic index was observed within the remaining tumours tissue of mice treated with $\mathrm{PAb}$ compared to mice injected subcutaneously with control IgG, *represents significant difference between PAb treatment group mice with the NS group and control IgG group mice $(P<0.05)$. Bar graph indicates the mean \pm SD $(n=5)$
A

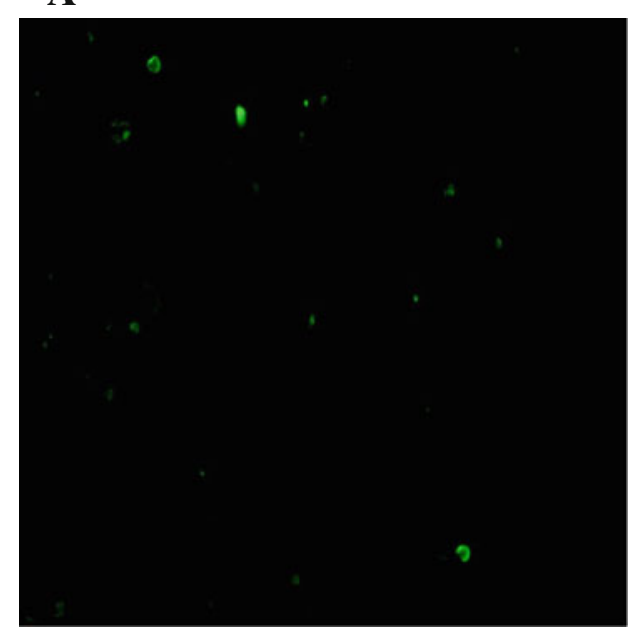

C

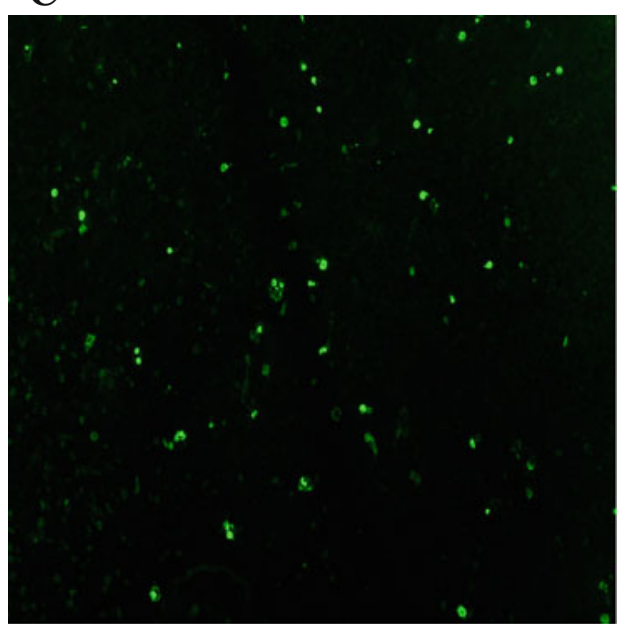

B

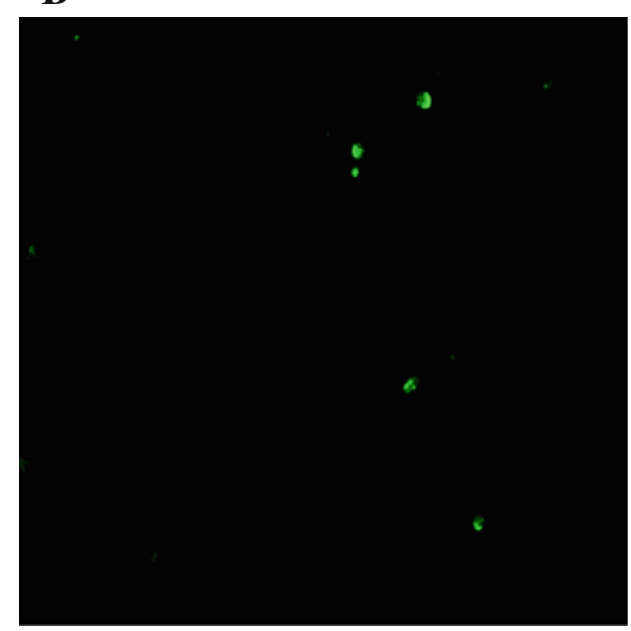

D

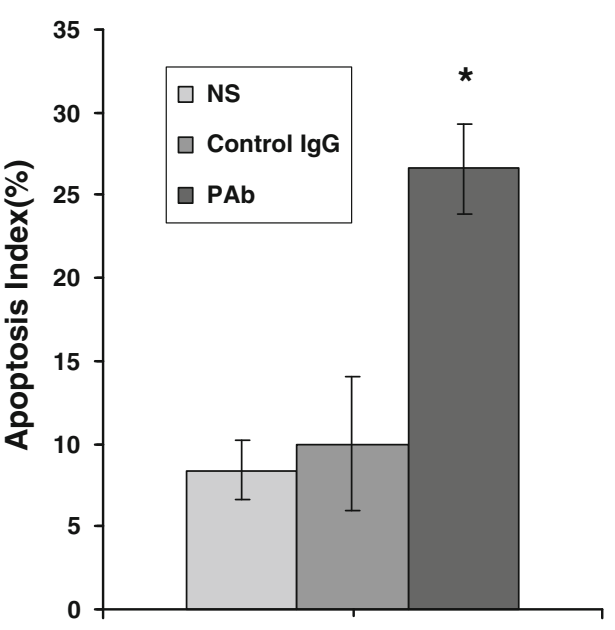

Treatment groups exposure to PAb decreased procaspase- 8 expression and increased caspase-3 and -9 activities in MPC-11 (Fig. 3f), which suggested that the mechanism of apoptosis involved caspases activation. This was supported by results demonstrating that pre-treatment with the pan-caspase inhibitor zVAD-fmk decreased apoptosis induced by PAb (Fig. 3g).

Most importantly, we found that PAb was inhibitory toward murine plasmacytoma cells while the growth of normal murine spleen cells ( $\mathrm{B}$ and $\mathrm{T}$ cells) was not inhibited (Fig. 2). These results suggest that our PAb could bind to specific multiple myeloma cell receptors resulting in apoptosis, while allowing immmunocytes (presumably free of $\mathrm{PAb}$ antigens) to assist in anti-tumour activity. Furthermore, spleen and lymph nodes are probably less efficient than myeloma tissue because plasma cells comprise only a small fraction of the total cell population in these organs [17].

Though the nature of the antigens recognized by the $\mathrm{PAb}$ is yet not known, Western blotting revealed several bands in multiple myeloma cell lines lysates (data not shown). Previous studies demonstrated that both ATG [16] and thymoglobulina [13] could recognize myeloma cellsurface proteins linked to apoptotic and growth factorreceptor pathways, including HLA-ABC, HLA-DR, CD32 (FcR $\gamma 2)$, CD19, CD20, CD30, CD38, CD95, CD126 (IL-6R), and CD138. We presume that the anti-myeloma activity was caused by PAb binding to at least some of these cell-surface molecules.

In summary, our results indicate that PAb can decrease tumour growth by binding multiple surface antigens on myeloma cells and promoting apoptosis. The results reported here suggest that $\mathrm{PAb}$ may have utility as a component of a clinical regimen for myeloma malignancies. Further careful clinical study will be needed to examine this possibility, although we confirmed that PAb can inhibit MM cell proliferation in mammals in vivo. Response to PAb therapy may vary among patients as clonal sensitivity to the multiple apoptosis pathways varies. 
In addition, the marrow microenvironment may afford additional protection from $\mathrm{PAb}$-induced apoptosis or complement-mediated lysis. We would suggest that any trial design include a component of in vitro and in vivo screening before PAb administration.

Acknowledgments This work was supported by National 973 Basic Research Program of China; Grant Number: 2006CB504302, 2006CB504303.

\section{Conflicts of interest None}

Open Access This article is distributed under the terms of the Creative Commons Attribution Noncommercial License which permits any noncommercial use, distribution, and reproduction in any medium, provided the original author(s) and source are credited.

\section{References}

1. Rajkumar SV, Gertz MA, Kyle RA, Greipp PR (2002) Current therapy for multiple myeloma. Mayo Clin Proc 77(8):813-824

2. Kyle RA, Rajkumar SV (2008) ASH 50th anniversary review: multiple myeloma. Blood 111(6):2962-2972

3. Rescigno M, Avogadri F, Curigliano G (2007) Challenges and prospects of immunotherapy as cancer treatment. BBA-Rev Cancer 1776(1): 108-123

4. Rosenblatt J, Avigan D (2008) Cellular immunotherapy for multiple myeloma. Best Pract Res Clin Haematol 21(3):559-577

5. Tanaka-Harada Y, Kawakami M, Oka Y, Tsuboi A, Katagiri T, Olga E et al (2010) Biased usage of BV gene families of T-cell receptors of WT1 (Wilms' tumor gene)-specific CD8+ Tcells in patients with myeloid malignancies. Cancer Sci 101:594-600

6. Mileshkin L, Prince HM, Seymour JF, Biagi JJ (2003) Serum MUC-1 as a marker of disease status in multiple myeloma patients receiving thalidomide. Br J Haematol 123(4):747-748

7. Jalili A, Ozaki S, Hara T, Shibata H, Hashimoto T, Abe M et al (2005) Induction of HM1. 24 peptide-specific cytotoxic T lymphocytes by using peripheral-blood stem-cell harvests in patients with multiple myeloma. Blood 106(10):3538-3545

8. Treon SP, Pilarski LM, Belch AR, Kelliher A, Preffer FI, Shima Y et al (2002) CD20-directed serotherapy in patients with multiple myeloma: biologic considerations and therapeutic applications. J Immunother 25(1):72-81

9. Tai YT, Catley LP, Mitsiades CS, Burger R, Podar K, Shringpaure R et al (2004) Mechanisms by which SGN-40, a humanized anti-CD40 antibody, induces cytotoxicity in human multiple myeloma cells: clinical implications. Cancer Res 64(8):28462852

10. Kumar S, Kimlinger TK, Lust JA, Donovan K, Witzig TE (2003) Expression of CD52 on plasma cells in plasma cell proliferative disorders. Blood 102:1075-1077

11. Chatterjee M, Chakraborty T, Tassone P (2006) Multiple myeloma: Monoclonal antibodies-based immunotherapeutic strategies and targeted radiotherapy. Eur J Cancer 42(11):1640-1652

12. Mihara M, Shiina M, Nishimoto N, Yoshizaki K, Kishimoto T, Akamatsu KI (2004) Anti-interleukin 6 receptor antibody inhibits murine AA-amyloidosis. J Rheumatol 31(6):1132-1138

13. Timm MM, Kimlinger TK, Haug JL, Kline MP, Greipp PR, Rajkumar SV et al (2006) Thymoglobulin targets multiple plasma cell antigens and has in vitro and in vivo activity in multiple myeloma. Leukemia 20(10):1863-1869
14. Adams GP, Weiner LM (2005) Monoclonal antibody therapy of cancer. Nat Biotechnol 23(9):1147-1158

15. Hideshima T, Mitsiades C, Tonon G, Richardson PG, Anderson KC (2007) Understanding multiple myeloma pathogenesis in the bone marrow to identify new therapeutic targets. Nat Rev Cancer 7(8):585-598

16. Zand MS, Vo T, Pellegrin T, Felgar R, Liesveld JL, Ifthikharuddin $\mathrm{JJ}$ et al (2006) Apoptosis and complement-mediated lysis of myeloma cells by polyclonal rabbit antithymocyte globulin. Blood 107(7):2895-2903

17. Watanabe T, Yagi Y, Pressman D (1971) Antibody against neoplastic plasma cells: I. specific surface antigens on mouse myeloma cells. J Immunol 106(5):1213-1221

18. Sainz IM, Isordia-Salas I, Espinola RG, Long WK, Pixley RA, Colman RW (2006) Multiple myeloma in a murine syngeneic model: modulation of growth and angiogenesis by a monoclonal antibody to kininogen. Cancer Immunol Immunother 55(7): 797-807

19. Trizio D, Cudkowicz G (1974) Separation of T and B lymphocytes by nylon wool columns: evaluation of efficacy by functional assays in vivo. J Immunol 113(4):1093-1097

20. Wei Y, Zhao X, Kariya Y, Fukata H, Teshigawara K, Uchida A (1994) Induction of apoptosis by quercetin: involvement of heat shock protein. Cancer Res 54(18):4952-4957

21. Damaj G, Mohty M, Vey N, Dincan E, Bouabdallah R, Faucher C et al (2004) Features of extramedullary and extraosseous multiple myeloma: a report of 19 patients from a single center. Eur J Haematol 73(6):402-406

22. Borghaei H, Smith MR, Campbell KS (2009) Immunotherapy of cancer. Eur J Pharmacol 625:41-54

23. Weiner LM, Dhodapkar MV, Ferrone S (2009) Monoclonal antibodies for cancer immunotherapy. Lancet 373(9668):10331040

24. Kapoor P, Greipp PT, Morice WG, Rajkumar SV, Witzig TE, Greipp PR (2008) Anti-CD20 monoclonal antibody therapy in multiple myeloma. Br J Haematol 141(2):135-148

25. Melero I, Hervas-Stubbs S, Glennie M, Pardoll DM, Chen L (2007) Immunostimulatory monoclonal antibodies for cancer therapy. Nat Rev Cancer 7(2):95-106

26. Tai YT, Li X, Tong X, Santos D, Otsuki T, Catley L et al (2005) Human anti-CD40 antagonist antibody triggers significant antitumor activity against human multiple myeloma. Cancer Res 65(13):5898-5908

27. Lundin J, Kimby E, Bjorkholm M, Broliden PA, Celsing F, Hjalmar V et al (2002) Phase II trial of subcutaneous anti-CD52 monoclonal antibody alemtuzumab (Campath-1H) as first-line treatment for patients with B-cell chronic lymphocytic leukemia (B-CLL). Blood 100(3):768-773

28. Zhang Q, Chen G, Liu X, Qian Q (2007) Monoclonal antibodies as therapeutic agents in oncology and antibody gene therapy. Cell Res 17(2):89-99

29. Newcombe C, Newcombe AR (2007) Antibody production: polyclonal-derived biotherapeutics. J Chromatogr B 848(1):2-7

30. Matsui W, Wang Q, Barber JP, Brennan S, Smith BD, Borrello I et al (2008) Clonogenic multiple myeloma progenitors, stem cell properties, and drug resistance. Cancer Res 68(1):190-197

31. Sharon J, Liebman MA, Williams BR (2005) Recombinant polyclonal antibodies for cancer therapy. J Cell Biochem 96(2):305-313

32. Wyllie AH (1992) Apoptosis and the regulation of cell numbers in normal and neoplastic tissues: an overview. Cancer Metastasis Rev 11(2):95-103

33. Arends MJ, Morris RG, Wyllie AH (1990) Apoptosis. The role of the endonuclease. Am J Pathol 136(3):593-608

34. Raff MC (1992) Social controls on cell survival and cell death. Nature 356:397-400 
35. Trauth BC, Klas C, Peters AM et al (1989) Monoclonal antibodymediated tumor regression by induction of apoptosis. Science 245(4915):301-305

36. Ayuk FA, Atassi N, Schuch G, Mina S, Fang L, Bokemeyer $\mathrm{C}$ et al (2008) Complement-dependent and complement- independent cytotoxicity of polyclonal antithymocyte globulins in chronic lymphocytic leukemia. Leukemia Res 32(8): $1200-1206$ 